DA. Revista de Documentación Administrativa

n० 284-285, mayo-diciembre 2009, pp. 11-31

ISSN: 0012-4494

\title{
El nuevo procedimiento sancionador de tráfico
}

\author{
Ramón Ledesma Muñiz \\ Subdirector General de Ordenación Normativa \\ Dirección General de Tráfico \\ raledesma@dgt.es
}

\begin{abstract}
Resumen
El nuevo procedimiento sancionador de tráfico es un artículo que presenta las cinco pretensiones u objetivos principales de la Ley 18/2009 basados todos ellos en la consecución de un nuevo procedimiento sancionador de tráfico. Dichas pretensiones pueden resumirse en los siguientes enunciados: 1. Atender el carácter masivo de los expedientes sancionadores en materia de tráfico con un procedimiento específico, diferente del procedimiento general; 2. Minimizar el tiempo entre la infracción y la sanción: la sanción rápida como elemento de seguridad activa en la conducción; 3. Reducir la litigiosidad por motivos de forma, no de fondo; 4. Ofertar al conductor en el procedimiento sancionador los derechos de acceso electrónico a los servicios públicos, consagrados por la Ley 11/2007; 5. Acercar la nueva realidad del "pago por uso" del vehículo a su gestión administrativa.
\end{abstract}

Palabras clave

Tráfico; Procedimiento administrativo; Infracción; Sanción; Legislación; España; 2009.

\section{The new disciplinary procedure of traffic}

\begin{abstract}
The new disciplinary procedure of traffic is an article that presents five pretensions or principal aims of the Law 18/2009 based all of them in the attainment of a new disciplinary procedure of traffic. The above mentioned pretensions can be summarized in the following statements: 1 . To attend to the massive character of the infraction dossiers in the subject traffic with a specific procedure, different from the general procedure; 2. To minimize the time between the infraction and the sanction: the fast sanction like element of active safety in the driving; 3. To reduce the litigiousness for motives of form, not of bottom; 4. To offer the driver in the disciplinary procedure the rights of electronic access to the public services guaranteed by the Law 11/2007; 5. To bring over the new reality of the "payment for use" from the vehicle to its administrative procedure.
\end{abstract}

\section{Key words}

Traffic; Administrative procedure; Infraction; Sanction; Legislation; Spain; 2009. 


\section{INTRODUCCIÓN}

El diccionario de la lengua de la Real Academia Española define el derecho como el "conjunto de principios y normas, expresivos de una idea de justicia y de orden, que regulan las relaciones humanas en toda sociedad y cuya observancia puede ser impuesta de manera coactiva".

Para aquel que no conoce la ciencia jurídica, la lectura conjunta de los términos "normas", "relaciones humanas" y "de manera coactiva” le llevará en muchas ocasiones y de una manera subconsciente a imaginar la norma de circulación y la multa de tráfico. $Y$ es aquí donde aparecen los tres datos referentes a esas "relaciones humanas" que fueron tenidos muy en cuenta por la Dirección General de Tráfico a la hora de diseñar el Proyecto de Ley de reforma de la Ley de Seguridad Vial en materia sancionadora (hoy Ley 18/2009, de 23 de noviembre).

El primer dato era el número de destinatarios finales de la norma. Es decir, de posibles infractores. Nada menos que 25.000.000 de personas constituyen el censo de conductores, y con él, de posibles infractores del procedimiento. En definitiva, la norma no se iba a dirigir a regular un procedimiento para unos pocos individuos en caso de litigio, sino que iba a ser "usada" diariamente por una multitud de conductores. Con este dato, y teniendo en cuenta que no todos los conductores son juristas, se trataba de diseñar una norma clara, sencilla y comprensible. Solo así podría ser adoptada, entendida y cumplida por el conductor.

El segundo dato es el número de veces que la norma se iba a aplicar, esto es, el número de expedientes sancionadores que generan las infracciones a la norma de tráfico. 15.000.000 de expedientes sancionadores al año, nada más y nada menos. De hecho, como ocurre en todos los países de nuestro entorno, la ley de tráfico es la norma más infringida.

La última cifra también cobraba especial relevancia: el número de gestores o aplicadores de la norma. Esto es, el número de administraciones con competencias sancionadora en materia de tráfico. Además de la Dirección General de Tráfico imponen sanciones de tráfico en nuestro país el Servei Català de Trànsit, Trafiko Vasco y 8.000 ayuntamientos. Con este número de gestores, la norma debía conseguir la mayor uniformidad posible, al objeto de que el conductor tuviese certeza jurídica en el castigo que la infracción de la norma conllevaba.

\section{LAS OBJETIVOS DE LA LEY 18/2009}

Las pretensiones u objetivos de la Ley 18/2009 pueden resumirse en cinco:

1. Atender el carácter masivo de los expedientes sancionadores en materia de tráfico con un procedimiento específico, diferente del procedimiento general. 
La puesta en marcha de la Ley 30/92, de 26 de noviembre, de Procedimiento Administrativo Común, dejó fuera, ya desde sus inicios, los expedientes derivados del ámbito tributario y los de la seguridad social. El motivo parecía claro: el volumen y especialidad de estos expedientes. Pues bien, en el año 2007, se generaron 95.861 infracciones al orden social, y en el ámbito tributario, 1.300.000 expedientes por infracciones a la Ley General Tributaria. Si tomamos los datos de los expedientes sancionadores por infracciones a la Ley de Seguridad Vial generados por la Dirección General de Tráfico, nos encontramos con algo más de 3.500.000 expedientes. Si a esto le unimos los expedientes por infracciones a la Ley de Seguridad Vial generados por el resto de administraciones con competencias en materia de tráfico (Ayuntamientos, Servei Català de Transit y Trafiko Vasco) nos encontramos con un total de 15.000.000 de expedientes sancionadores. En definitiva, y como ocurre en todos los países de nuestro entorno, la ley de tráfico es la ley más infringida, la que más expedientes sancionadores genera por infracciones a la propia Ley. Y, por otra parte, lo que justifica la aparición de la norma específica: si las otras dos materias con esos volúmenes tenían una legislación especial, ¿cómo no la iba a tener la especialidad de tráfico con el volumen generado?

\section{Minimizar el tiempo entre la infracción y la sanción: la sanción rápida como elemento de seguridad activa en la conducción.}

Una de las reglas básicas de los países con mejores resultados en siniestralidad es la existencia de un sistema de autoridad de la vigilancia y disciplina del tráfico que funcione, y además, que funcione rápido. No se trata de imponer multas o castigos más altos, sino de que estos sean justos y rápidos. En definitiva, si el conductor sabe que el que la hace, la paga, y la paga rápido, modifica su comportamiento al volante. En resumen, el proceso sancionador ágil y rápido previene el accidente.

En este sentido, puede decirse que la lentitud y falta de agilidad del procedimiento administrativo sancionador en materia de tráfico había quedado especialmente en evidencia por su hermano mayor, el proceso penal que juzga los delitos en materia de tráfico. La introducción del juicio rápido en el año 2002 (Ley 38/2002, de 24 de octubre, de reforma parcial de la Ley de Enjuiciamiento Criminal) y la reforma de los delitos en materia de seguridad vial operada por la Ley Orgánica 15/2007, de 30 de noviembre, habían provocado que la justicia penal dejase en evidencia la justicia administrativa.

El ejemplo más evidente lo constituye la ingesta de alcohol durante la conducción. Desde el 2 de diciembre de 2007 (fecha de entrada en vigor de la Ley Orgánica 15/2007), si el conductor detectado bajo la influencia de bebidas alcohólicas superaba la tasa de 0,6 mg/l de aire espirado, su acción devenía en un delito. Con la configuración de los juicios rápidos, el conductor es citado a juicio en un plazo no superior a una semana, obteniendo en esa misma citación una condena de privación del derecho a conducir (por un tiempo mínimo de 8 meses) y una multa económica (normalmente, no inferior a 1.000 euros). Esta situación se produce en el $98 \%$ de los delitos de 
alcohol. Desde el punto de vista de la seguridad vial ("el que la hace la paga, y la paga rápido") mejor imposible.

Sin embargo, si conduces bajo la influencia de bebidas alcohólicas por debajo de 0,6 mg/l, pero por encima de $0,25 \mathrm{mg} / \mathrm{l}$ (0,15, en el caso de conductores noveles y profesionales) nos encontrábamos con una infracción administrativa. Teniendo en cuenta los plazos de alegaciones y recursos (cuyo respeto era necesario, aunque el conductor quisiese cerrar el procedimiento) el tiempo mínimo para suspender su derecho a conducir y detraer los puntos al conductor era de cinco meses. Con cierta frecuencia, entre 6 y 8 . Y en muchas ocasiones, casi de 2 años. Desde el punto de vista de la seguridad vial ("el que la hace la paga, y la paga rápido"), peor imposible. Se genera entonces en la conducción la denominada "sensación de impunidad": como sé que el castigo no llega, o llega muy tarde, me comporto de otro modo al volante.

\section{Reducir la litigiosidad por motivos de forma, no de fondo.}

No debemos engañarnos: la mayoría de las denuncias formuladas (bien por agentes de la autoridad, bien de oficio por la administración - radares fijos -) se confirman a favor de la Administración. A diferencia de lo que ocurre al juzgar un robo o un hurto (donde el juez busca algún indicio que mínimamente relacione al autor del hecho con el crimen), aquí la relación ha quedado acreditada por la visión nada menos que de un agente de la autoridad o de un medio homologado, certificado y verificado de detección de infracciones. Poco margen cabe en cuanto a la duda en la comisión del hecho. Por este motivo, las alegaciones en el procedimiento se dirigen precisamente contra éste, contra el procedimiento. Como regla general no se cuestiona que se haya cometido el hecho, sino el proceso para juzgar el hecho. Si este es largo y farragoso, da lugar a mayor litigiosidad. Mejorar el proceso, haciéndolo claro, sencillo y comprensible es disminuir la litigiosidad del mismo.

\section{Ofertar al conductor en el procedimiento sancionador los derechos de ac- ceso electrónico a los Servicios Públicos, consagrados por la Ley 11/2007.}

En nuestra vida diaria, cada vez es más frecuente sustituir la comunicación postal por una comunicación electrónica. Gestionamos mejor nuestra vida diaria si todo lo que llega tradicionalmente a nuestro buzón postal llega a nuestro buzón electrónico. Desde el recibo del agua o la luz hasta el aviso de cobro del impuesto sobre bienes inmuebles pueden recibirse en nuestro ordenador, adoptando en ese momento y a través del mismo ordenador las decisiones correspondientes: consultas, pagos, archivo digital del documento.....

Exactamente lo mismo ocurre con las notificaciones referentes a expedientes sancionadores de tráfico. Las notificaciones de infracciones de tráfico se entregan 14 por los carteros en las viviendas por las mañanas, cuando no suele haber nadie en ellas. En una de cada dos notificaciones es necesario acudir a la oficina de correos a 
recoger la notificación, de la que te han dejado aviso en el buzón. Desplazamientos y esperas son entonces necesarios para recoger la notificación. La nueva ley pretende, para aquellos que lo deseen, sustituir ese domicilio físico de notificaciones (con los problemas que ello genera) por un "domicilio electrónico", pudiendo gestionar desde tu propio ordenador las notificaciones que antes gestionabas en formato papel.

Algo similar ocurre con las notificaciones que no pueden practicarse en el domicilio, y que se remiten, de acuerdo con la Ley 30/92 al Boletín Oficial de la Provincia donde se cometió el hecho y al Tablón de Edictos del Ayuntamiento del infractor. Aunque la notificación edictal es correcta, lo cierto es que el infractor no se ha enterado de la misma, y por tanto el conductor queda desprotegido de sus derechos. La Ley 18/2009 sustituye esa notificación edictal en formato papel por una notificación digital en una página web, siempre consultable por el ciudadano y fácilmente accesible.

\section{Acercar la nueva realidad del "pago por uso" del vehículo a su gestión ad- ministrativa.}

Es cada vez más frecuente en el uso de las cosas que estas no se adquieran en propiedad, sino que simplemente se pague por el uso que de ellas se haga durante un cierto tiempo. Con los vehículos ocurre así. Esta circunstancia provoca que la tradicional asociación de ideas titular del vehículo-conductor del mismo vaya desapareciendo. La matriculación de vehículos a nombre de personas jurídicas (cerca ya del 40\%), y la creciente introducción de la figura del renting o arrendamiento a largo plazo del vehículo obligan a configurar el Registro de Vehículos contemplando estas realidades, permitiendo de este modo que las administraciones se dirijan en el procedimiento sancionador contra quien realmente es el "usuario habitual" del vehículo.

\section{LA RELEVANCIA JURÍDICO-FORMAL DE LA NORMA.}

La importancia y trascendencia de la reforma del procedimiento sancionador del tráfico establecido en la Ley 18/2009 se hace patente en elementos tales como los cambios en otras normas con rango de ley, ajenas a la de seguridad vial, pero que se modifican expresamente con motivo de esta reforma.

En primer lugar, la propia ley general de procedimiento administrativo de nuestro país. La Disposición final primera de la Ley 18/2009, de 23 de noviembre, modifica la Ley 30/92, de 26 de noviembre, de Régimen Jurídico de las Administraciones Públicas y del Procedimiento Administrativo Común, incorporando una nueva Disposición adicional octava bis, bajo el título "Procedimiento sancionador en materia de tráfico y seguridad vial":

Los procedimientos administrativos para la imposición de sanciones por infracciones en materia de tráfico, circulación de vehículos a motor y seguridad vial, se regi- 
rán por lo dispuesto en su legislación específica y, supletoriamente, por lo dispuesto en esta Ley".

En segundo lugar, la normativa legal que regula el ámbito tributario en nuestro país. La Disposición final tercera de la Ley 18/2009, de 23 de noviembre, modifica la Ley 58/2003, de 17 de diciembre, General Tributaria, dejando redactado el párrafo j) del apartado 1 del artículo 95 (al objeto de permitir la cesión de datos a las administraciones de tráfico para la mejora de las notificaciones) de la citada Ley del siguiente modo:

“i) la colaboración con órganos o entidades de derecho público encargados de la recaudación de recursos públicos no tributarios para la correcta identificación de los obligados al pago y con la Dirección General de Tráfico para la práctica de las notificaciones a los mismos, dirigidas al cobro de tales recursos"

Finalmente, también la Ley 18/2009 modifica la normativa general del seguro obligatorio del automóvil. La Disposición final segunda de la Ley 18/2009 dispone la supresión de la multa por no llevar el recibo del seguro del automóvil, y el traslado de la competencia sancionadora por infracciones a la regulación del seguro del automóvil de los Delegados y Subdelegados del Gobierno a los Jefes Provinciales de Tráfico (art. 3. 1. b)2 y 3 del Real Decreto Legislativo 8/2004, de 29 de octubre:

"2. Para sancionar la infracción serán competentes los Jefes Provinciales de Tráfico o, en las Comunidades Autónomas que tengan transferidas competencias ejecutivas en materia de tráfico y circulación de vehículos a motor, los órganos previstos en la normativa autonómica, en los términos establecidos en el artículo 71 del texto articulado de la Ley sobre Tráfico, Circulación de Vehículos a Motor y Seguridad Vial, aprobado por Real Decreto Legislativo 339/1990, de 2 de marzo.

3. La infracción se sancionará conforme a uno de los procedimientos sancionadores previstos en el texto articulado de la Ley sobre Tráfico, Circulación de Vehículos a Motor y Seguridad Vial."

\section{LAS INFRACCIONES}

Este es probablemente el ámbito de la Ley de Seguridad Vial que menos modificaciones ha sufrido. En este sentido, todos somos plenamente conscientes de aquel conjunto de acciones que son contrarios a la normativa de tráfico y que ya se encuentran perfectamente tipificados: conducir con exceso de alcohol, por encima de los límites de velocidad establecidos, utilizar el teléfono móvil,....

Por encima de la percepción ciudadana de los conductas contrarias al hecho de la circulación, y adentrándonos ya en la tipificación jurídica de las infracciones de trá16 fico, varios elementos son destacables. 
En primer lugar, la relación concreta de infracciones y su clasificación. La Ley de Seguridad Vial, ya en su redacción inicial en el año 1990, tipificó las infracciones en tres grupos (leves, graves y muy graves), pero dejó sin embargo un "cajón” de sastre en las denominadas infracciones del artículo 67.2. Se trataba de un grupo de infracciones relacionadas con las autorizaciones administrativas derivadas del hecho de la circulación (conducción sin la autorización correspondiente, sin matrícula, con un vehículo que no se sometía a la inspección técnica,....). La Ley 17/2005, por la que se regula el sistema del permiso por puntos, hizo desaparecer definitivamente este cajón, incluyendo y distribuyendo su contenido dentro de la tradicional clasificación en leves, graves y muy graves. Ninguna novedad aporta en este punto la reforma de la Ley 18/2009.

En segundo lugar, se tipifican algunas infracciones nuevas, unas fruto del avance de la técnica y otras, del nuevo sistema de responsabilidad que la Ley impone en determinadas infracciones al titular del vehículo, al conductor o entidades con actividades que afecten a la seguridad vial.

Entre las primeras:

- conducir un vehículo programando el navegador (de hecho los navegadores cada vez introducen sistemas técnicos que impiden su uso cuando detectan la circulación del vehículo)

- circular en un tramo a una velocidad media superior a los límites establecidos (se trata de dar cobertura legal a los denominados "radares de tramo", mecanismos de vigilancia y disciplina del tráfico con cierta tradición en algunos países europeos)

- incumplir la obligación de todo conductor de verificar que las placas de matrícula no presenten obstáculos que impidan o dificulten su lectura (los modernos sistemas de vigilancia y disciplina del tráfico se basan en la lectura de la matrícula con sistemas OCR)

Entre las segundas:

- que el titular de un vehículo permita que alguien que nunca tuvo permiso o licencia de conducción conduzca su vehículo (se implica al titular del vehículo en la circulación del mismo)

- participar o colaborar en la colocación o puesta en funcionamiento de elementos que alteren el normal funcionamiento del uso del tacógrafo o del limitador de velocidad (se implica al titular del vehículo en la manipulación del tacógrafo)

- incumplir las normas que regulan actividades industriales que afectan de manera directa a la seguridad vial (actividades como manipular el cuentakilómetros encontrarían aquí cobertura para su sanción). 
En tercer lugar, destacar el hecho de que por primera vez la Ley de Seguridad Vial tipifica expresamente una infracción leve. Tradicionalmente, se definían como todas las cometidas contra las normas de circulación que no se calificasen expresamente como graves y muy graves. La Ley 18/2009 incorpora esta definición tradicional pero añade (fruto de la tramitación parlamentaria en el Senado) una infracción leve expresamente: no hacer uso por parte de los usuarios de bicicletas de los elementos y prendas reflectantes. Se trata de llamar la atención al usuario de bicicleta (que cada vez se impone con mayor fuerza) la importancia de ver y dejarse ver en la vía.

Finalmente, señalar también la inclusión dentro de las infracciones muy graves de una relación "especial” de las mismas que podríamos calificar como "infracciones industriales": se trata de tipificar en un punto específico (el artículo 65.6 LSV) aqueIlas infracciones que se desarrollan habitualmente bajo alguna actividad industrial o empresarial y que pueden implicar consecuencias especialmente graves para la seguridad vial (ej: no instalar la señalización de obras).

\section{LAS SANCIONES}

Puede decirse que el cambio comienza realmente aquí. Dos principios básicos inspiran la nueva estructura de las sanciones por infracciones a la legislación de tráfico:

1. claridad y sencillez: con cerca de 25 millones de conductores "potenciales infractores", las reglas de juego deben estar muy claras. El conductor debe tener siempre el conocimiento y la seguridad jurídica de las consecuencias que acarreará su comportamiento infractor

2. la sanción como elemento seguridad activa. Determinados elementos del vehículo ayudan a mejorar nuestra manera de conducir, evitando la producción del accidente. El ejemplo más conocido el ABS, que ayuda a mejorar nuestro comportamiento al frenar el vehículo. La sanción de tráfico funciona del mismo modo. Si el conductor la conoce, sabe que es justa y sabe también que se impondrá de una manera rápida y efectiva, modifica y mejora su comportamiento al volante.

Las características principales del nuevo catálogo de sanciones son las siguientes:

1. Establecimiento de una multa económica fija para cada conducta.

La redacción tradicional de la Ley de Seguridad Vial establecía sanciones variables en función de las infracciones y la Administración que las impusiese. Las infracciones leves eran castigadas con multa de hasta 90 euros, las infracciones graves de 91 a 300 euros y las muy graves de 301 a 600 euros. En la práctica, cada Administración con competencia sancionadora (cada Ayuntamiento) establecía su propio bare18 mo o cuadro de multas, lo que provocaba un castigo diferente para el conductor no 
en función de la conducta, sino del sitio físico o lugar territorial donde se encontrase. Algún ejemplo era muy significativo. En algún municipio, la multa por conducir con teléfono móvil era de 95 euros, mientras que en el municipio colindante era de 295 euros. Con el objeto de facilitar al conductor una idea clara de las consecuencias de su comportamiento, el importe de la multa económica se hace ahora fijo: 200 euros para las sanciones graves y 500 euros para las sanciones muy graves. Fruto de las aportaciones municipales a la tramitación de la Ley, las infracciones leves (fundamentalmente urbanas y referidas fundamentalmente a la fluidez del tráfico, no a la seguridad) pueden graduarse, con un importe máximo de 100 euros.

Para no obviar el principio de graduación de la sanción, básico en el ejercicio de la potestad sancionadora, la Ley de Seguridad Vial establece ahora en su artículo 66 la posibilidad de incrementar la sanción establecida en un $30 \%$, atendiendo a la gravedad y trascendencia del hecho.

2. No se elevan las cuantías de las sanciones para la mayoría de las infracciones.

La obtención de mejores resultados en siniestralidad vial no va ligada a un aumento del importe de las sanciones, sino a una mejor gestión de las mismas. Por este motivo, no era objeto de esta Ley revisar la cuantía de las sanciones (el importe de las sanciones no ha variado desde el año 1990, fecha de creación de la Ley de Seguridad Vial). Es más, en muchas de las sanciones, fruto de la reducción del 50\%, el importe final de la sanciones baja de precio. El ejemplo más claro es el de las infracciones por pequeños excesos de velocidad. El 90\% de las infracciones de velocidad provenientes de los radares fijos son pequeños excesos de velocidad (circular en autopista con límite de $120 \mathrm{~km} / \mathrm{h}$ a $138 \mathrm{~km} / \mathrm{h}$ ) que hasta la entrada en vigor de la ley se castigaban con 70 euros de multa económica (100 euros, con reducción del 30\%, 70 euros). Ese 90\% de infracciones de los radares fijos baja su importe hasta los 50 euros (100 euros, con reducción del 50\%, 50 euros). En este sentido, no hay que olvidar que el $85 \%$ de las sanciones de tráfico se pagan con reducción.

3. Supresión de la sanción de suspensión temporal de permiso de conducción.

La regulación tradicional en nuestro país de las sanciones de tráfico para las infracciones graves y muy graves consistía en imponer una multa económica y la suspensión temporal del permiso de conducción, de 1 a 3 meses. En el año 2005 nuestro país implanta el sistema de permiso por puntos, que tan buenos resultados había dado en las países de la Unión Europea que lo tenían establecido. De este modo, desde el 1 de julio de 2006 (fecha de entrada en vigor del sistema de puntos) el conductor podía ser sancionado en determinadas infracciones graves y muy graves con multa económica y retirada de permiso de conducción, y además, con retirada de puntos. De este modo, confluían tres consecuencias administrativas fruto de la actividad infractora del conductor.

Tres años después de la implantación del permiso de conducir por puntos, sus resultados son más que evidentes. Es por tanto el sistema de puntos el que ha traído 
los resultados esperados en siniestralidad vial. En estas circunstancias, la suspensión temporal del permiso de conducción se convertía en una tremenda carga para el ciudadano, pero que no aportaba nada al fin de la reducción de la accidentalidad (en el año 2008 se suspendió el permiso de conducir a los conductores por un total de 180.000 meses). Por este motivo, la Ley 18/2009 la hace desaparecer.

4. La sanción al titular por no cumplir con su obligación de identificar al conductor se modula en función de la infracción originaria.

Como ocurre en el resto de la países de nuestro entorno, cada vez es más frecuente la instalación de sistemas de vigilancia y disciplina del tráfico donde no existe detención del conductor en el momento de la infracción. Posteriormente, la Administración requiere al titular del vehículo al que se ha detectado circulando infringiendo para que indique el conductor que hacía uso del vehículo. A partir de ese momento, la Administración se dirige contra el conductor infractor.

En este sentido, toma un papel imprescindible en el procedimiento sancionador la identificación por parte del titular del vehículo del conductor infractor. La importancia de la obligación motivó que la Ley 17/2005 calificase como muy grave la infracción consistente en no identificar al conductor, estableciendo una sanción económica de hasta 1.500 euros. Esta situación provocaba que, por ejemplo, el incumplimiento de la obligación de identificar al conductor infractor de un estacionamiento indebido (sancionable con 90 euros) podía terminar (y de hecho, se ha producido más de un episodio) en una sanción por no identificar de 1.500 euros.

La Ley 18/2009 modifica la sanción por no identificar, haciéndola depender de la infracción originaria. De este modo, la infracción por no identificar será del doble de la originaria, si la infracción es leve, y del triple, si es grave o muy grave.

5. Sanción especial para quien use inhibidor de radar.

Se trata de aquellos conductores que deciden instalar sistemas (valorados en más de 3.000 euros en muchos casos) con el propósito de eludir los sistemas de vigilancia y disciplina del tráfico. Se trata por tanto de conductores que se desplazan con la intención premeditada de "multinfringir". Al objeto de cumplir la regla básica de todo procedimiento sancionador de que infringir no salga más rentable que cumplir la norma, la Ley establece una sanción especial para este supuesto por un importe de 6.000 euros (y 6 puntos, de acuerdo con el sistema de puntos recogido en el Anexo II).

6. Sanciones especiales para las actividades industriales contrarias a la seguridad vial.

La gravedad de las actividades industriales que pueden afectar a la seguridad vial exige sanciones especiales. Entre 3.000 y 20.000, así como la posibilidad de suspen20 der la autorización administrativa por la que ejercen su actividad. 


\section{SUJETOS RESPONSABLES}

Como no podía ser de otro modo, la ley mantiene el principio general de que el responsable de la infracción es el autor del hecho cometido. Si conducimos con exceso de alcohol por encima de las tasas legalmente establecidas, será el conductor el sujeto sobre el que se dirigirá el procedimiento sancionador y sobre el que finamente recaerá la sanción.

Ahora bien, la ley establece algunas especialidades, unas ya incluidas en reformas anteriores de la Ley de Seguridad Vial (reformas del año 2001 y 2005), y otras en la Ley 18/2009. Estas especialidades se concretan del siguiente modo:

a) en las infracciones por no llevar el casco de protección obligatorio, si el pasajero de la motocicleta no hace uso del mismo, el responsable no será él, sino el conductor. Esta responsabilidad se limita a la multa económica, no incluye la detracción de puntos.

b) de las infracciones cometidas por el conductor menor, es responsable solidario en la cuanto a la multa económica el padre o tutor (artículo introducido a través de la Ley 19/2001)

Además de las especialidades anteriores, la Ley introduce dos elementos novedosos que tendrán un papel relevante en el sistema de atribución de responsabilidad.

En primer lugar, el arrendatario a largo. Cada vez es más frecuente en la sociedades modernas la utilización de bienes en régimen de pago por uso, no en sistema de propiedad. En el caso de los vehículos, esta fórmula se concreta en la figura del renting, o arrendamiento a largo plazo. En estos supuestos, los vehículos pertenecen al propietario (en muchas ocasiones, entidades financieras) que los arriendan a las empresas por un periodo de entre 2 y 5 años. Es decir, el titular-propietario del vehículo es el arrendador, y el usuario del mismo el arrendatario.

En estas circunstancias, no sirve la tradicional asociación de ideas que identificaba al propietario del vehículo con su conductor. Las infracciones de los radares fijos son el ejemplo más claro de esta disociación. En la configuración tradicional titularconductor, las notificaciones de las infracciones de los radares fijos se dirigían a quién era normalmente usuario directo del mismo (el conductor coincidía con el propietario, o al menos pertenecía a su entorno familiar). Con los vehículos en régimen de renting, la Administración debe dirigirse al titular del vehículo, que debe comunicar a la Administración la empresa arrendataria, para que este a su vez identique al conductor del mismo y pueda la administración dirigir el procedimiento sancionador contra él. La consecuencia es que el principio de "rapidez" en el conocimiento de la sanción por parte del conductor se rompe, habida cuenta que el proceso de notificaciones y comunicaciones titular- arrendatario- conductor supone llegar a éste último en plazo de 5 meses. 
Con este objeto, la ley introduce la obligación a los arrendadores de vehículos a largo plazo de comunicar al Registro de vehículos el arrendatario del mismo. De este modo, las Administraciones con competencia sancionadora se dirigirán directamente a la empresa arrendataria (es decir, directamente al entorno del conductor), evitando de este modo un eslabón en la cadena de identificaciones y comunicaciones, acudiendo directamente a quien es usuario habitual del vehículo.

La segunda de las novedades es la figura del conductor habitual. Son muchas las ocasiones en que el titular del vehículo no hace uso de él, y si en cambio una de las personas del entorno del mismo es el que habitualmente usa el vehículo (familiar, trabajador de la empresa,... ) En estas circunstancias, la Ley permite ahora al titular del vehículo (o al arrendatario a largo plazo, si consta en el Registro de Vehículos) incluir en el Registro de Vehículos al conductor que hace uso del mismo. Desde el momento de su inclusión en el Registro, las Administraciones se dirigirán directamente contra el conductor habitual, evitando de este modo un eslabón en la cadena de identificaciones y comunicaciones, acudiendo directamente a quien es usuario habitual del vehículo. La figura del conductor habitual funciona como la del titular o arrendatario, pudiendo identificar siempre al conductor que en ese momento hacía uso del mismo. En el supuesto de que no comunique nada, será responsable el propio conductor.

Novedad también importante es la alteración del sistema de responsabilidad en las denuncias por estacionamiento indebido. Hasta la Ley 18/2009, la responsabilidad de la infracción se atribuía al conductor, con lo que era necesario en toda multa por estacionamiento (cerca de 8.000.000 de denuncias anuales) averiguar el conductor del mismo. La primera notificación se dirigía al titular del vehículo, que si no comunicaba el conductor que en ese momento hacía uso del mismo, se encontraba con una denuncia de entre 300 y 1500 euros por no haber identificado al conductor. En este sentido, hay que recordar que la notificación de los estacionamientos indebidos se realiza casi siempre a través de la vía postal, donde en 1 de cada 3 ocasiones no es posible que el infractor pueda recibir la notificación, con la correspondiente imposibilidad de responder a la Administración. La ley atribuye en principio la responsabilidad al titular del vehículo, salvo en el caso de que este designe un conductor responsable de la acción. En este caso, la administración se dirigirá contra él.

\section{LOS PROCEDIMIENTOS}

Una de las novedades más interesantes de la reforma del procedimiento sancionador de tráfico es la existencia de dos posibles caminos o iter procedimentales para que la infracción se convierta en sanción: el procedimiento abreviado y el procedimiento ordinario.

Sin perjuicio de entrar en los detalles de cada uno de ellos, es importante dejar

22 aquí constancia de dos características básicas de esta dualidad. 
En primer lugar, el elector del procedimiento no es la administración, sino el propio infractor. Es éste el que decide por cual de los caminos quiere optar. Tras su decisión, será la Administración la que tenga que obrar de acuerdo con el camino elegido.

En segundo lugar, la similitud con la disyuntiva que el infractor (en este caso, el presunto delincuente) tiene en los supuestos de delitos que pueden acogerse al juicio rápido penal. La filosofía en ambos casos es similar: cometido el hecho y detectado como infracción/delito, la autoridad competente para dictar la sanción a imponer ofrece una rebaja sustantiva en la condena a cambio de cerrar el proceso/procedimiento. Algunos datos avalan el funcionamiento del sistema penal como sistema que ahora se traslada al ámbito administrativo. En concreto, en el caso del delito de tráfico consistente en la conducción bajo la influencia de bebidas alcohólicas, el 98\% de los detenidos optaron por acogerse al denominado juicio rápido, cerrando el proceso al obtener la reducción de la condena en un tercio (en el caso de la privación del derecho a conducir, en la mayoría de las ocasiones la condena de 1 año queda reducida a 8 meses de privación).

Finalmente, esta doble opción a que se enfrenta el infractor tampoco es nueva en el derecho administrativo del tráfico. De hecho, no es sino un paso más en la reducción que tradicionalmente se hacía en el importe de la multa (30\%). Lo cierto es que el sistema ya funcionaba, habida cuenta de que el $75 \%$ de las infracciones que se abonaban en periodo voluntario (no en ejecutiva) lo hacían en los 30 primeros días con reducción.

Entrando ya en la doble opción que ahora se ofrece al infractor de tráfico, empezaremos por la primera de ellas: el procedimiento abreviado.

Recogido en el artículo 80, consiste básicamente en ofrecer al infractor la posibilidad de terminar con el expediente sancionador si abona la sanción antes del plazo de 20 días desde su notificación. En las denuncias formuladas por el Agente, el plazo comienza al día siguiente de serle entregada la denuncia, al tener está valor de notificación. En el caso de las denuncias formuladas por correo postal (ej. denuncias provenientes de los radares fijos), desde la recepción de la notificación por el infractor. En el supuesto de denuncias notificadas a través de la Dirección Electrónica Vial, el plazo comienza tras el acceso a la misma por parte del infractor.

En el supuesto de optar por el procedimiento abreviado, y por tanto, abonar la denuncia en 20 días las consecuencias son las siguientes:

1. El importe de la sanción se reduce en un $50 \%$.

2. La terminación del procedimiento, sin necesidad de dictar resolución expresa, el mismo día en que se realiza el pago.

3. Se agota la vía administrativa, siendo recurrible únicamente ante el orden jurisdiccional contencioso-administrativo. 
4. La denuncia, si no lleva puntos, no constará como antecedente para el infractor (ej: el 90\% de las denuncias de los radares fijos son pequeños excesos de velocidad, y por tanto infracciones graves, pero que solo llevan aparejada multa económica, no puntos).

5. Si lleva puntos, éstos se detraerán al día siguiente del pago (desde el momento del pago, la sanción es firme, produciendo plenos efectos desde el día siguiente).

Este hecho, que aparentemente puede beneficiar a la Administración por cerrar el expediente sancionador, beneficia fundamentalmente al infractor. El motivo es que el plazo para recuperar los 12 puntos, cuando nos han detraído alguno, es de dos años desde que se produjo la detracción. Hasta el momento actual, la detracción no podía producirse hasta que no transcurría el periodo de presentación del recurso de alzada (30 días), aunque hubiese pagado, ya que la firmeza no se producía hasta ese momento. La ley establece que el pago provoca la firmeza de la sanción, pudiendo entonces comenzar a partir del día siguiente el plazo de 2 años para que la Administración le devuelva los doce puntos.

6. Se renuncia al derecho a formular alegaciones y recursos. En forma similar a lo que ocurre en el juicio rápido penal (donde termina el proceso con el allanamiento del delincuente), el pago en periodo abreviado provoca la terminación del expediente sancionador, sin poder de este modo formular alegaciones y recursos.

En definitiva, el procedimiento abreviado no es sino un do ut des, un pacto tácito entre Administración y administrado para terminar con todo el procedimiento sancionador.

Pero el infractor puede no estar de acuerdo con la denuncia formulada. En este caso, debe optar por el procedimiento ordinario. En realidad, no es sino el procedimiento sancionador tal y como tradicionalmente venía existiendo. El infractor dispone de un plazo (20 días) para formular las alegaciones, pruebas o informes que tenga por oportuno. El instructor del expediente podrá requerir cuantas pruebas tenga por oportuno, al objeto de mejor decidir su resolución. Finalmente, la autoridad sancionadora dictará resolución confirmando o denegando la denuncia formulada. Dictada la resolución, ésta es firme una vez notificada al infractor, detrayéndose por tanto los puntos y debiendo proceder al pago (sin reducción) en el plazo de quince días. De no hacerlo, se remitirá a la vía ejecutiva para su exacción en vía de apremio.

Dentro de este apartado "procedimientos", debemos incluir la importante novedad que introduce la Ley 18/2009 y que, por primera vez, castiga la inactividad del infractor. Señala el nuevo artículo 81.5 de la Ley de Seguridad Vial que, "Si el denunciado 24 no formula alegaciones ni abona el importe de la multa en el plazo de quince días natu- 
rales siguientes al de la notificación de la denuncia, esta surtirá el efecto de acto resolutorio del procedimiento sancionador. En este supuesto, la sanción podrá ejecutarse transcurridos treinta días naturales desde la notificación de la denuncia"

El artículo supone una especial novedad en el derecho administrativo, y más aún en el sancionador. Como en el caso de la "elección del procedimiento", es el propio infractor el que decide optar por esta opción, al no ejercer sus derechos formulando alegaciones ni tampoco abonando la sanción para cerrar el expediente. Dos son los mensajes que este artículo envía al conductor que ha infringido:

1. Si te formulan una denuncia, reacciona. Alega, o paga, pero reacciona, actúa. La inactividad solo provocará que comience contra el infractor el proceso de la vía ejecutiva.

2. Se rompe el deber de dictar resolución expresa cuando el ciudadano ha optado por ello. Tendemos a escenificar a la Administración como "la mala" y al ciudadano como "el bueno". En este caso, la respuesta del legislador surge probablemente como respuesta a esta pregunta: ¿debe la administración volver a dirigirse al infractor (con todo el proceso de trabajo y notificaciones que ello supone) si éste ha optado por desentenderse de la propia administración?

Esta procedimiento no se aplica a todas las infracciones. De acuerdo con el párrafo $2^{\circ}$ del artículo 81.5, solo es aplicable a las infracciones leves, graves que no detraigan puntos, y graves y muy graves cuya notificación se efectuase en el acto de la denuncia.

\section{LAS NOTIFICACIONES}

Aspecto importante en el ejercicio del derecho administrativo es el de la notificación de las diferentes documentos generados en el procedimiento sancionador (iniciación, resolución... ). Los actos administrativos, cualesquiera que sea su contenido, no comienzan a producir efectos hasta que no se han notificado correctamente al administrado. En este sentido, la notificación, dentro del ámbito del procedimiento sancionador de tráfico, cobra especial relevancia en las infracciones captadas por sistemas de vigilancia y disciplina del tráfico (radares fijos, cámaras de vigilancia de acceso al centro histórico de la ciudad...) En este tipo de infracciones, donde no hay Agente de la Autoridad que detenga al infractor, la notificación es la primera noticia que tiene el autor del hecho de que ha cometido una infracción. Si la notificación falla (ausente, desconocido, remisión posterior al Boletín Oficial de la Provincia...) el procedimiento sancionador fracasa: la multa probablemente se cobre a través de la vía ejecutiva, pero el infractor ha quedado desprotegido de toda posibilidad de actuar en el procedimiento sancionador (alegar, recurrir,pagar con descuento...). 
Con este objeto, se introducen dos novedades importantes.

a) La Dirección Electrónica Vial. Puede definirse como la sustitución del domicilio físico de notificaciones del procedimiento sancionador por un domicilio electrónico. Las Administraciones con competencia sancionadora remiten las notificaciones al domicilio físico de notificaciones que consta en los Registros de la Dirección General de Tráfico. Ese domicilio físico genera problemas, habida cuenta de los errores en la información del mismo (número, calle... ), de la entrega por los servicios postales, de la diversidad de domicilios... De hecho, una de cada tres notificaciones en vía postal presenta algún tipo de problema que obliga a remitir la notificación al Boletín Oficial de la Provincial de la provincia donde se cometió el hecho infractor, sin que el conductor se entere de su contenido. La Dirección Electrónica Vial es un sitio web, un buzón electrónico dentro de la página de la Dirección General de Tráfico, que, una vez activado por el ciudadano, permite a las Administraciones sustituir el envío de la notificación postal en formato papel por un documento (PDF) a ese sitio web.

Varias notas importantes se refieren a esa Dirección Electrónica Vial.

1. Como ocurre con el acceso al buzón físico de nuestro domicilio (que requiere de llave para proteger nuestra correspondencia) la Dirección Electrónica Vial requiere también de llave (en este caso, el DNI electrónico u otro tipo de certificado digital) para la creación y acceso al mismo. De este modo, la correspondencia electrónica queda también protegida y solo podrá ser consultada por el destinatario de la misma.

2. Al objeto de evitar que el ciudadano se preocupe por entrar cada día en su Dirección Electrónica Vial para consultar si existen notificaciones pendientes, la DEV cuenta con un sistema de avisos al correo electrónico personal y al teléfono móvil. En estos dos medios se genera un aviso indicando que debes recoger una notificación en tu Dirección Electrónica Vial.

3. La Dirección Electrónica Vial se convierte en el medio natural de comunicación entre el conductor/titular del vehículo y la Administración, en todos los aspectos relacionados con el vehículo o su permiso de conducción. De este modo, además de las notificaciones de las infracciones y sanciones, a la Dirección Electrónica Vial se generarán avisos referentes a la próxima renovación del permiso de conducción, a la caducidad de la ITV, del seguro del vehículo...

4. La Dirección Electrónica Vial es única para todas las autorizaciones administrativas de que disponga un titular de vehículo o de permiso de conducir. Es decir, una Dirección Electrónica Vial, un DNI o un CIF. De este modo, si una 
empresa se da de alta en la Dirección Electrónica Vial, todas las notificaciones de todos los vehículos de que disponga la flota se notificarán en esa Dirección Electrónica Vial.

5. La Ley establece que la obtención de esa Dirección Electrónica Vial es voluntaria para las personas físicas, y obligatoria para las personas jurídicas que matriculen vehículos nuevos a partir del 25 de noviembre.

6. En principio, la Dirección Electrónica Vial entra en vigor el 25 de noviembre como método obligatorio de notificación (caso de activarse por el ciudadano) para las notificaciones de la Dirección General de Tráfico, Servei Català de Trànsit y Trafiko Vasco. En definitiva, para las notificaciones por infracciones cometidas en la carretera, no en la ciudad. Para las infracciones cometidas en el ámbito urbano, los Ayuntamientos disponen hasta el 25 de mayo de 2012 para irse incorporando al sistema. A partir de esta fecha, si el denunciado cuenta con Dirección Electrónica Vial, las notificaciones solo serán válidas si se practican en ella

\section{b) El Tablón Edictal de Sanciones de Tráfico (TESTRA).}

De acuerdo con los establecido en el artículo 59 de la Ley 30/92, las notificaciones que no puedan practicarse, se harán por medio de anuncios ene. Tablón de edictos del Ayuntamiento de su último domicilio, en el "Boletín Oficial del Estado", de la Comunidad Autónoma o de la Provincia, según cual sea la Administración de la que proceda el acto a notificar, y el ámbito territorial del órgano que lo dicto. Los procedimientos sancionadores de tráfico son un claro ejemplo del uso de este tipo de notificación, que sin embargo, teniendo efectos formales, no provoca ninguna garantía material de que la notificación ha sido conocida por el infractor (el ciudadano no se levanta por las mañanas a consultar los 52 Boletines Oficiales de la Provincia por si pudiera haber alguna notificación pendiente).

Al objeto de sustituir esa notificación en el Boletín Oficial de la Provincia de la que el ciudadano no tiene en la práctica conocimiento, se crea el Tablón Edictal de Sanciones de Tráfico. De acuerdo con lo establecido en el art. 78, las notificaciones que no puedan efectuarse en la Dirección Electrónica Vial o en el domicilio indicado, se practicarán en el Tablón Edictal de Sanciones de Tráfico (TESTRA). Transcurrido el periodo de veinte días naturales desde que la notificación se hubiese publicado en el TESTRA, se entenderá que ésta ha sido practicada, dándose por cumplido dicho trámite y continuándose con el procedimiento.

Las características principales pueden describirse del siguiente modo:

1. Es una página web donde de una manera ordenada se incorporan todas las notificaciones del procedimiento sancionador que no han podido practicarse en el domicilio del interesado. 
2. Como ocurre con el acceso de los ciudadanos a los Boletines de la provincia, este acceso es público. De este modo, al entrar en la página web del TESTRA, con solo teclear nuestro Documento Nacional de Identidad o nuestra matrícula podremos saber si existe alguna multa pendiente de notificar.

3. Como ocurre con la Dirección Electrónica Vial, el TESTRA cuenta con un sistemas de avisos y alertas al correo electrónico personal y al teléfono móvil que te permite no tener que consultar permanentemente el mismo. En la propia página web, con solo facilitar tu correo electrónico y tu teléfono móvil se recibirá un aviso de que una notificación se ha publicado en el TESTRA.

4. En definitiva, puede definirse como un "macroboletín oficial de la provincia" ordenado y en formato electrónico, donde aquel que desea saber si tiene alguna notificación pendiente, puede hacerlo. Hasta el momento no era posible: era necesario consultar todas y cada una de las páginas de todos los boletines provinciales.

5. No obstante la mejora que supone el TESTRA, debe quedar claro que es "la solución menos mala" para la práctica del ejercicio de la potestad sancionadora. La publicación en el TESTRA no es sino el fracaso del ejercicio de la potestad sancionadora por parte de las administraciones con competencias en materia de tráfico que no han conseguido hacer llegar la correspondiente notificación al ciudadano.

6. La sustitución de la publicación en BOP y en el Tablón de Edictos del Ayuntamiento por una única publicación en el TESTRA, será hace obligatoria para las todas las notificaciones de las infracciones de tráfico que se cometan en la carretera a partir del 25 de noviembre (tramitadas por tanto por DGT, Servei Català de Transit y Trafiko Vasco). Para las infracciones cometidas en el ámbito urbano, la obligatoriedad no se produce hasta el 25 de mayo de 2012, aunque podrán irse incorporando paulatinamente.

\section{LOS RECURSOS}

Otro de los elementos del nuevo procedimiento sancionador que constituye una auténtica revolución en el derecho administrativo sancionador es la supresión del recurso de alzada y su sustitución por el recurso de reposición.

Establece la Ley 18/2009 que "contra las resoluciones sancionadoras, podrá interponerse recurso de reposición, con carácter potestativo, en el plazo de un mes contado desde el día siguiente al de su notificación". Son varias las voces críticas que afirman la pérdida de derechos y garantías para el conductor que se produce como consecuencia de la supresión del recurso de alzada. En el polo opuesto, es también importante

28 el sector de la doctrina que criticaba la figura del recurso de alzada alegando que la 
Administración se revisaba a si misma, con todo lo que ello conlleva, e indicaba que la actividad de la Administración debe someterse directamente a los tribunales. Sin embargo, dos datos avalan la correcta adopción de la medida:

1. Cerca del $95 \%$ de las infracciones de tráfico se confirman a favor de la Administración. Es decir, la denuncia del Agente o captada a través del radar fijo era correcta y se encontraba bien tramitada. En definitiva, no por existir más instancias en vía administrativa la multa se va a confirmar a favor del ciudadano.

2. El recurso de alzada era presentado frecuentemente con el objeto de demorar la detracción de puntos en el permiso de conducir del infractor. Solo cuando el procedimiento era firme se produce la detracción de puntos (y esto se producía -aunque el infractor pagase y quisiese cerrar el expediente- cuando se resolvía el recurso de alzada o transcurría el periodo de 30 días para su presentación) Con la supresión del recurso de alzada, la resolución sancionadora pasa a ser firme desde el día siguiente a su notificación al denunciado. En ese momento se produce ya la detracción de puntos, y el denunciado dispone del plazo de quince días para abonar la sanción con su importe íntegro antes de que se produzca su remisión a la vía ejecutiva.

Por otra parte, aparece ahora la figura del recurso de reposición, con bastante tradición en el ámbito local. Sin embargo, los puntos ya se han detraído y se ha abierto ya el plazo para ejercer el recurso contencioso administrativo.

\section{LAS MEDIDAS CAUTELARES}

Las tradicionalmente denominadas "medidas provisionales" pasan ahora a denominarse medidas cautelares, denominación más acorde con el objeto de las mismas, que no es otro que el de asegurar la eficacia de la resolución sancionadora y garantizar la seguridad en la circulación vial.

Muchas de las medidas se encontraban ya recogidas en la normativa anterior. Sin embargo, existen algunas novedades:

1. En primer lugar, la posibilidad de limitar la disposición sobre los vehículos de los que uno es titular cuando consten como impagadas más de cuatro sanciones firmes en vía administrativa por infracciones graves o muy graves. (art. 87.1) En definitiva, aquel conductor que "multinfrinja", y además decida no abonar la sanción, no podrá vender su vehículo. En este sentido, cobra especial relevancia que, como ocurre en el ámbito inmobiliario, todo posible adquirente de un vehículo pueda informarse de la existencia de esta limitación de disposición. En caso contrario, la compraventa civil no podría transformarse en cambio de titularidad administrativa, con las consecuencias que ello conlleva. 
2. La misma regla es aplicable a los titulares de los vehículos, por las infracciones que a ellos se les atribuyan y que figurarán como impagadas en el historial del vehículo (ej: la existencia de cuatro o más sanciones por no identificar al conductor del vehículo).

De las limitaciones de disposición señaladas anteriormente se exceptúan la baja temporal o definitiva de vehículos, habida cuenta de que el fin en este caso del titular es no circular con el vehículo, sino deshacerse del mismo (no permitir esta medida fomentaría el abandono de vehículos en la vía urbana).

Incluido en el capítulo de las medidas cautelares se encuentra el tratamiento residual del vehículo (art. 86). Poco o nada tiene realmente que ver este precepto con el procedimiento sancionador, aunque en muchas ocasiones la medida se realiza cuando el titular del vehículo lo abandona precisamente por no hacer frente a una medida de inmovilización dentro de un procedimiento sancionador.

El artículo 86 recoge la facultad de la Administración para deshacerse de aquellos vehículos que han quedado abandonados en la vía, por múltiples razones. Asimismo, recoge una vieja reivindicación de los talleres y depósitos de vehículos, que ven ocupado el espacio de sus instalaciones por viejos vehículos llevados allí por accidente o avería y cuyo titular nunca más volvió a recogerlos. La Administración permite al titular del recinto privado deshacerse de ellos, siempre y cuando siga el procedimiento legalmente establecido.

Asimismo, se dispone la posibilidad de que los vehículos abandonados (cualesquiera sea la causa), en vez de abandonarse pasen a formar parte de los servicios de vigilancia y disciplina del tráfico.

\section{LA EJECUCIÓN DE LAS SANCIONES}

Tras la firmeza de la sanción, el infractor dispone de un periodo de quince días naturales para proceder al abono de la misma. Vencido el plazo de ingreso establecido en el apartado anterior sin que se hubiese satisfecho la multa, su exacción se llevará a cabo por el procedimiento de apremio.

Varias son las novedades introducidas en este capítulo con respecto a la legislación anterior:

1. En primer lugar, el plazo de prescripción de las sanciones pasa de uno a cuatro años. Se trata de "perseguir" a aquellos individuos que, una vez transcurrido todo el iter procedimental, deciden permanecer al margen de la ley, sin abonar las sanciones ya firmes. En este caso, la Administración Tributaria podrá perseguir la deuda por un periodo de hasta cuatro años. 
2. El cómputo y la interrupción de la prescripción, así como todo el procedimiento de exacción, será el establecido en la Ley General Tributaria y su normativa de desarrollo, sin que exista ninguna especialidad (como hasta el momento) recogida en la Ley de Seguridad vial.

3. Se establece la posibilidad de exigir la responsabilidad subsidiaria del titular del vehículo.

Recibido: 23 de noviembre de 2010

Aceptado: 10 de enero de 2011 
